\title{
FATORES RELACIONADOS A LESÕES EM ATLETAS DE BOLÃO 16 CATEGORIA FEMININO NA CIDADE DE CAÇADOR/SC
}

\author{
FACTORS RELATED TO INJURIES IN ATHLETES OF NINEPIN FEMALE CATEGORY
}

IN THE CAÇADOR'S CITY STATE OF SANTA CATARINA

\author{
Andressa Paganini ${ }^{1}$ \\ Elaine Caroline Boscatto ${ }^{2}$ \\ Adriano Slongo ${ }^{3}$
}

Recebido em: 23 maio 2017 Aceito em: 22 abr. 2018

RESUMO: O bolão 16 é uma modalidade esportiva onde o objetivo é derrubar nove pinos posicionados ao final de uma pista de madeira com uma bola maciça. Exige técnica, inteligência e concentração. Tendo em vista a escassez de estudos na literatura e a necessidade de aprofundar conhecimentos neste esporte específico, foi realizada a presente pesquisa para investigar a incidência de lesões e fatores relacionados às mesmas em atletas do sexo feminino, praticantes da modalidade na cidade de Caçador/SC. Tratase de estudo transversal, descritivo, com análise quanti-qualitativa dos dados. Foi aplicado um questionário de formulário próprio para investigar informações pessoais, índice de massa corporal, tempo de jogo, dores e lesões articulares, hábitos relacionados à prática da modalidade e de outras atividades físicas. Participaram do estudo 11 atletas, com idades entre 18 a 56 anos e média de IMC $27,25 \mathrm{~kg} / \mathrm{m} 2$. O tempo de prática variou de 10 meses a 27 anos. A maioria das participantes utiliza o braço direito para o lançamento e a perna esquerda para o apoio ao final do arremesso, demonstrando um movimento harmônico. No entanto, possuem alto índice de lesões/dores articulares, tendo a articulação mais acometida por dores a do joelho, seguida de quadril. Sobre o hábito de aquecimento e alongamento, todas as atletas afirmaram que o realizam; contudo foi verificado que a metade das atletas tem como prática de atividade física exclusiva o bolão, sendo necessário o incentivo a práticas preventivas voltadas ao esporte, além de orientação para a técnica adequada evitando desgaste físico entre outras consequências.

Palavras-chave: Esportes. Traumatismos em atletas. Articulações.

ABSTRACT: The ninepin it's a sports mode where play mens and womens, with the objetive is drop the nine pin in the end of wooden track, with the solid ball. It requires technique, intelligence and concentration. Given the scarcity of studies in the literature and the need to deepen knowledge in this specific sport, the present research was carried out to investigate the incidence of injuries and related factors in female athletes, practitioners of the sport in the city of Caçador in Santa Catarina state. This is a crosssectional, descriptive study with quantitative qualitative data analysis. A questionnaire was used to investigate personal information, body mass index, playing time, pain and

\footnotetext{
1 Graduanda em Educação Física pela Universidade Alto Vale do Rio do Peixe-UNIARP, E-mail: paganini.andressa@hotmail.com.

2 Mestre em Atividade Física Relacionada a Saúde, Universidade Alto Vale do Rio do Peixe-UNIARP, E-mail: elaine.caroline@uniarp.edu.br.

${ }^{3}$ Mestre em Saúde e Ambiente, Universidade Alto Vale do Rio do Peixe-UNIARP,

E-mail: fisioterapia@uniarp.edu.br.
} 
joint injuries, habits related to the practice of the sport and other physical activities. Eleven athletes, aged 18 to 56 years, with a mean BMI of 60,075 pounds ft.sq, participated of this study. Regarding the training time, it ranged from 10 months to 27 years. Most athletes use the right arm for the throw and the left leg for support at the end of the pitch, demonstrating a harmonious movement. However, they have a high index of lesions/joint pain, and the joint is more affected by pain in the knee, followed by hip pain. On the warm-up and stretching habit, all athletes stated that they perform it. However, it was verified that half of the athletes have a practice of exclusive physical activity the ninepin, being necessary the incentive to preventive practices oriented to the sport, besides orientation for the appropriate technique avoiding physical wear among other consequences.

Keywords: Sports. Athletic injuries. Joint.

\section{INTRODUÇÃO}

A modalidade de bolão 16 é um esporte coletivo, ainda pouco divulgado no Brasil e está presente nos estados onde a colonização alemã predomina, mais precisamente no Rio Grande do Sul, Santa Catarina, Paraná, São Paulo e Rio de Janeiro (FEDERAÇÃO CATARINENSE DE BOCHA E BOLÃO - FCBB, 2016, WEB).

É um esporte onde participam homens e mulheres sem limite de idade. Geralmente, a prática do bolão está concentrada em clubes e sociedades particulares, onde sempre esteve ligado aos frequentadores desses locais, de onde foram surgindo os atletas.

O bolão 16 é um esporte bastante envolvente e prazeroso, pois além da técnica, é necessário jogar com inteligência, concentração e paciência. Consiste em derrubar os nove pinos posicionados no final de uma prancha (pista) de madeira com uma bola maciça.

Em um jogo de bolão 16, um atleta vai arremessar ao menos 40 bolas, tornando esses arremessos, um gesto repetitivo.

Considerando o gesto repetitivo de cada jogada, a biomecânica do movimento e as articulações exigidas para cada movimento, surgiu a necessidade de investigar a incidência de lesões e os fatores relacionados as mesmas, em atletas do sexo feminino praticantes de bolão 16 no município de Caçador/SC. Ressalta-se a escassez de estudos na literatura relacionados ao bolão 16, principalmente sobre possíveis lesões que possam acometer atletas desta modalidade; e também, fazer com que este estudo possa ajudar a analisar e corrigir algum movimento inadequado, tanto no aprendizado motor quanto em atletas que já competem, até mesmo prevenir lesões que possam afastar atletas da modalidade.

O estudo tem como objetivo, investigar a incidência de lesões em atletas do sexo feminino que jogam bolão 16; buscando informações pessoais das atletas; verificando hábitos relacionados a prática esportiva; pesquisando as principais lesões que acometem as atletas da modalidade de bolão 16 e recolhendo informações para orientar boa postura e técnica adequada de movimento. 


\section{MATERIAL E MÉTODO}

A pesquisa utilizou o método quanti e qualitativo, caracterizando como estudo transversal e descritivo.

A população do estudo compreendeu atletas da modalidade de bolão 16, categoria feminino da cidade de Caçador/SC. A amostra da pesquisa foi de todas as participantes da modalidade, que compreendem 11 atletas.

Foi aplicado o questionário em 11 atletas que atualmente jogam na equipe de Caçador/SC, todas do sexo feminino. Para a coleta dos dados de peso e altura, foi utilizado uma balança digital e uma fita métrica respectivamente; onde as atletas foram mensuradas sem o calçado, vestindo calça e camiseta. Os dados foram coletados em dias de treino, terças e quintas-feiras e sábado, na Sociedade Caçadorense de Bochas onde é o local de treino.

O instrumento de coleta de dados foi por meio de questionário elaborado pela própria autora. As atletas foram investigadas em dias e horários de treino da modalidade, que ocorrem nas terças-feiras e quintas-feiras, das $18 \mathrm{~h} 30 \mathrm{~min}$ as $20 \mathrm{~h} 30 \mathrm{~min}$ e aos sábados a partir das 16 horas, na Sociedade Caçadorense de Bochas.

O estudo foi aprovado pelo Comitê de Ética da Universidade Alto Vale do Rio do Peixe-UNIARP sob o número de CAAE: 55295916.8.00005593. Todas as participantes receberam e assinaram o Termo de Consentimento Livre e Esclarecido, aceitando participar do estudo.

Os dados foram analisados por meio de estatística descritiva, média e desvio padrão, utilizando programa estatístico SPSS Statistics 20.

\section{RESULTADOS E DISCUSSÃO}

Esta pesquisa investigou todas as atletas de bolão $16(n=11)$, representando a equipe de Caçador/SC. As atletas possuem idades entre 18 a 56 anos, com uma média de $39,91( \pm 12,55)$ anos de idade.

A Tabela 1 apresenta os resultados de Peso, Estatura e IMC da amostra:

Tabela 1 - Representação do Peso, Estatura e Massa Corporal das atletas de Bolão 16 do município de Caçador/SC - 2016.

\begin{tabular}{ccccc}
\hline Indicadores & Mínimo & Máximo & Média & Desvio Padrão \\
\hline Peso $(\mathrm{Kg})$ & 51,60 & 86,40 & 72,54 & 11,74 \\
Estatura $(\mathrm{m})$ & 1,54 & 1,71 & 1,63 & 0,04 \\
IMC $\left(\mathrm{kg} / \mathrm{m}^{2}\right)$ & 19,69 & 31,52 & 27,25 & 4,09 \\
\hline
\end{tabular}

Fonte: Paganini, 2016.

Segundo a classificação da World Health Organization (WHO, 2000, p. 242) para o 
Índice de Massa Corporal (IMC), 27,3\% ( $n=3)$ das atletas têm o IMC classificado como normal, 45,5\% ( $n=5)$ das atletas têm o IMC mostrando índice de sobrepeso e 27,3\% ( $n=$ 3) das atletas têm o IMC mostrando índice de Obesidade classe I - que apresenta risco moderadamente aumentado para comorbidades. Conforme Bouchard (2003, p.7) "a diferença básica entre obesidade e sobrepeso reside na maior porcentagem de massa corporal (como gordura no obeso). Em outras palavras, a expansão dos tecidos magros livres de gordura não foi acompanhada pelo crescimento do tecido adiposo".

Todas as atletas de bolão têm um tempo de treino significativo: a que treina a menos tempo tem 10 meses de participação na equipe, em contrapartida, a atleta que treina a mais tempo, tem 27 anos de participação na equipe, resultando em um tempo médio de participação na modalidade de 7 anos.

Conforme os dados coletados, todas as atletas lançam a bola com o braço direito. Já quanto a perna de apoio ao final do lançamento, $81,8 \%(n=9)$ atletas se apoiam na perna esquerda (perna contrária do braço que lançamento) e $18,2 \%(n=2)$ se apoiam na perna direita.

Sobre as dores articulares durante ou após o treino ou jogo de bolão, $81,8 \%(\mathrm{n}=$ 9) das atletas afirmaram sentirem dores nas articulações, sendo que a articulação do joelho foi a mais citada e em ambos os lados (joelho direito e esquerdo), seguido da articulação do quadril, coluna e ombro.

A tabela 2 apresenta a frequência de respostas de dor, dividido por região e membro.

Tabela 2 - Representação de relato de dor por articulação e região das atletas de Bolão 16 do município de Caçador/SC - 2016.

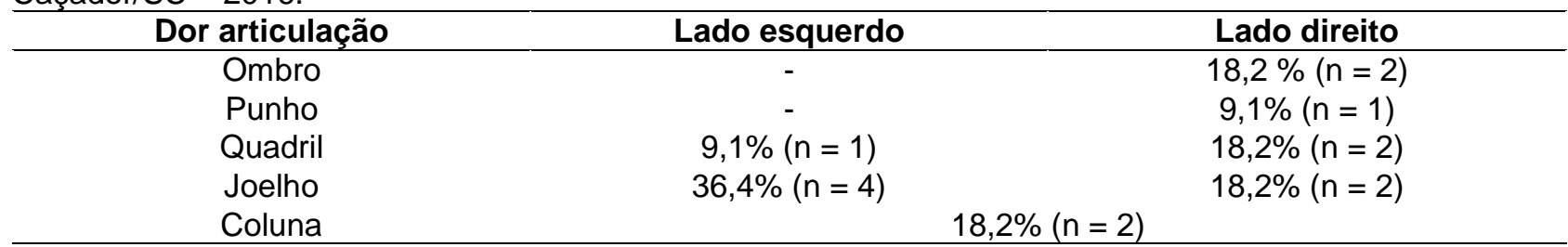

Fonte: Paganini, 2016

Apenas duas atletas afirmaram não sentirem dores articulares. Ainda sobre as lesões, nenhuma das atletas realizou cirurgia referente a lesão no esporte.

Todas as atletas afirmaram realizar alongamento antes do início do treino ou se em competições, antes dos jogos, e $36,4 \%(n=4)$ realizam alongamento antes e depois. Com relação ao aquecimento antes do início do treino ou em competições, a maioria $81,8 \%$ ( $n=$ 9) afirmou realizar o mesmo.

As atletas também foram questionadas sobre a prática alternativa de atividade física, além do bolão 16 , onde $54,6 \%(n=6)$ afirmou praticar outras atividades além do esporte bolão, incluindo atividades em academias, lutas, natação, bem como caminhadas com os mais diversos objetivos: lazer, prevenção e tratamento e inclusive como deslocamento. 
Conforme os dados obtidos na amostra, a maioria das atletas citaram que sentiam dores na articulação do joelho. Embora não tenha sido encontrado estudos específicos sobre a modalidade bolão 16 para comparar resultados, analisando a mecânica do movimento do corpo no jogo/treino de bolão, pode-se afirmar que o joelho sofre um impacto na hora de soltar a bola na pista, pois existe uma linha limite a ser respeitada no jogo e muitos atletas acabam por "parar" bruscamente muito em cima da linha para não sofrer penalidades, não tendo espaço para dar ao menos um passo depois do arremesso o que poderia diminuir o impacto nessa articulação. Como o joelho é uma articulação pouco estável e bastante solicitada nas práticas esportivas em geral, pois age com movimentos variados como mudança de direção, corridas, aceleração e desaceleração, agachamentos entre outros movimentos, ele fica sujeito a maior número de lesões do que qualquer outra articulação do corpo.

As lesões no joelho podem chegar a cerca de $15 \%$ de todas as lesões no esporte (TRIA, 2002). Walker (2010, p. 177) cita ainda que "um estresse repetitivo pode causar inflamação do tendão, especialmente sob contração, como ocorre durante a aceleração ou a desaceleração". O Autor ainda acrescenta que essa desaceleração pode levar a uma subluxação ou deslocamento da patela, pois a mesma desliza para fora do seu sulco do fêmur e não limita a mobilidade; o ligamento cruzado anterior (LCA) também é geralmente lesionado em esportes em que há mudanças de direção e/ou impactos na articulação, em ambas as situações, as lesões causam dor e inchaço local (WALKER, 2010).

Também é possível verificar entre os dados que a maioria das atletas que afirmaram sentir dores na articulação do joelho, estão com o IMC classificatório entre sobrepeso e obesidade grau 1. Em alguns estudos realizados por Pereira Júnior e Lima apud Almeida e Pereira Júnior (2010, p. 90) "concluíram que o sobrepeso e a obesidade possuem relação significativa para o aparecimento da dor anterior no joelho, ocasionando disfunções musculoesqueléticas e limitações nas atividades de vida diária e prática esportiva". Em relação ao tempo de jogo, também podemos considerar que as lesões podem estar ligadas a este fator, pois as atletas realizam um gesto repetitivo a cada jogada, repetindo inúmeras vezes durante os anos de treinos e/ou jogos; além de compensação de movimentos realizados de forma incorreta ou má posturas que acabam em desgaste físico/articular desnecessário; porém se analisarmos os relatos das atletas, o tempo de treino de cada uma delas varia muito e mesmo assim, há relatos de dores articulares em atletas novas e atletas que jogam a mais tempo.

Outro fator interessante a ser discutido é que analisando o fundamento do pêndulo, uma das articulações mais recrutadas para o arremesso é a do ombro, porém entre as atletas, o ombro teve um índice baixo de lesões, ficando abaixo do quadril e coluna. "Pode ser justamente esta adaptação muscular ao esporte que previne lesões, pois não há presença de dor, lesões capsulo-ligamentares e músculos-articulares" (PINTO, 2002, p. 46). E "analisando o complexo articular do ombro, observa-se que o gestual desportivo respeita a liberdade de movimento das articulações que compõem o complexo articular do ombro" (CAILLIET apud PINTO, 2002, p. 47). Pinto (2002, p. 49) também cita que "o próprio 
movimento de 'pêndulo' do ombro (movimento de balanceio) é realizado livremente [...], a articulação glenoumeral trabalha em sua livre amplitude de movimento inibindo a hipótese de sobrecarga articular".

É interessante ressaltar que as articulações do joelho e ombro participam diretamente da técnica de jogo da modalidade, mas ações inadequadas podem refletir em dores e/ou lesões em outras articulações, como relatadas pelas atletas: quadril, coluna e punho.

Analisando os dados apresentados, podemos observar que a grande maioria das atletas faz alguma atividade física a parte do treino de bolão, porém, são poucas atletas que realizam treinamento de força com o intuito de prevenir alguma possível lesão.

O treinamento de força é bastante utilizado para o fortalecimento dos músculos e articulações e ganho de massa muscular. E é importante que esse treinamento esteja presente em todos os esportes, garantindo um bom condicionamento físico para o atleta melhorando capacidades como força, resistência muscular e flexibilidade (WALKER, 2010).

O treinamento de força é muito eficaz para a prevenção de lesões em atletas, ele melhora a força dos músculos e os fortalecem, além de fortalecer as articulações e ossos, ajudando assim a manter o corpo alinhado e protegido durante a execução dos movimentos ou sob impacto, através da sobrecarga imposta durante o treinamento de força, os ossos, articulações e ligamentos ficam mais flexíveis e absorvem melhor o choque e/ou impacto durante os movimentos (WALKER, 2010).

Desequilíbrios musculares também são causas comuns de lesões em atletas e afetam articulações e ossos devido a tração não usual que move a articulação fora do natural, isso ocorre porque os músculos mais fortes levam a articulação tracionar nessa direção causando estiramento de ligamentos ou enrijecimento deles. Sendo assim, o treinamento de força ajuda a prevenir esses efeitos, equilibrando os músculos (WALKER, 2010).

Tão importante quanto o treinamento de força são as atividades de alongamento e aquecimento antes dos treinos e jogos. Segundo Walker (2010, p.27) "o alongamento é uma atividade simples e eficaz que ajuda a melhorar o desempenho atlético, diminui a probabilidade de lesão e minimiza a dor muscular". O autor também comenta que "os benefícios de uma amplitude de movimento estendida incluem conforto elevado, maior capacidade de movimentação livre e uma diminuição de nossa suscetibilidade a distensão ou lesão a eles".

$\mathrm{O}$ aquecimento antes da atividade física prepara tanto mente e corpo, ajudando a aumentar a temperatura corporal e muscular, tornando a musculatura relaxada e flexível. Eleva a frequência cardíaca e a frequência respiratória, aumentando o fluxo sanguíneo melhorando a distribuição de oxigênio e nutrindo os músculos que estão em atividade. A eficiência do aquecimento auxilia na preparação dos músculos, tendões e articulações para as atividades esportivas e minimizando a probabilidade de ocorrerem lesões em atletas. $O$ alongamento estático é bastante benéfico para a flexibilidade geral, incluindo todos os 
principais grupos musculares. Durante o alongamento estático, o corpo deve ficar numa posição que o músculo que está sendo alongado sofra tensão. Esse tipo de alongamento deve ser incluído no início do aquecimento, pois existem estudos recentes que mostram efeitos adversos envolvido na contração do músculo afetando atletas que requerem potência e velocidade. (WALKER, 2010).

\section{CONSIDERAÇÕES FINAIS}

O estudo envolveu todas as atletas da equipe da cidade de Caçador/SC. São atletas que possuem tempo significativo de jogo e já possuem técnica de jogo, têm seus fundamentos bem acentuados nas suas ações e nas jogadas. O estudo concluiu que $81,8 \%$ das atletas da equipe possuem dores articulares, podendo ser causa de futuras lesões, principalmente nas articulações que mais apareceram no estudo: joelho, quadril, coluna, ombro e punho.

Foi investigado as informações pessoais das atletas e hábitos na prática do bolão 16. A maioria das atletas possui um movimento corporal harmônico (membros superiores com membros inferiores e tronco), arremessando a bola com o braço direito e fazendo o apoio com a perna esquerda. Porém, mesmo assim, as atletas possuem um índice de lesões/dores articulares alto. Algumas até mostraram sentirem dores em mais de uma articulação.

Poucas atletas realizam algum treinamento de força. Sendo que a prática do bolão 16 aliada a aplicação dos treinamentos de força podem contribuir muito para a redução e prevenção de lesões nas atletas da equipe de Caçador/SC, pois além de aumentar a resistência muscular, a força muscular, desenvolver músculos e proteger as articulações, há também um aumento de massa magra e flexibilidade do atleta.

Outra questão para que se possa diminuir as lesões nas articulações mais afetadas, no caso o joelho, podendo também ser incluído o quadril e coluna, seria analisar a atleta individualmente para orientar uma possível adequação a técnica de jogo, adequar as passadas e o espaço, corrigir possíveis compensações de movimentos, tirando possíveis vícios nas jogadas das atletas.

Ao final este estudo, pode-se afirmar a necessidade de se investir em mais pesquisas na área da modalidade de bolão 16 , conhecimento da biomecânica nos movimentos empregados no jogo, melhor organização de treinamento para a modalidade, pois a falta de pesquisas relacionadas ao tema e o esporte atrasa o desenvolvimento das equipes, crescimento e o fortalecimento deste esporte no geral.

Também, pretende-se dar continuidade no estudo com as atletas de todas as equipes do estado de Santa Catarina, verificando a incidência de lesões e quais são, mostrando fontes de prevenção podendo até diminuir a evasão de atletas deste esporte devido as limitações causadas pelas lesões, ajudando a alavancar o esporte bolão 16 . 


\section{REFERÊNCIAS}

ALMEIDA, Rosana F. PEREIRA JÚNIOR, Altair A. Avaliação Funcional do Joelho em Praticantes de Musculação. Conexões: Revista da Faculdade de Educação Física da UNICAMP. Campinas, v. 8, n. 2, p. 83-92, maio/ago. 2010.

ASSOCIAÇÃO DOS BOLONISTAS DE ITAJAÍ - ABI. História do Bolão. Disponível em:<http://www.bolao16.com.br/index.php/components/com_phocagallery/assets/images/ modules/mod_gk_tab/templates/components/index.php?option=com_content\&view=article \&id=59\&ltemid=82>. Acesso em: 07 mar. 2016.

BOUCHARD, Claude. Atividade Física e Obesidade. Barueri: Manole, 2003.

FEDERAÇÃO CATARINENSE DE BOCHA E BOLÃO - FCBB. História. Disponível em: $<$ http://fcbb.com.br/site/modalidades.php?tipo=bolao16\#historia> Acesso em: 10 mar. 2016.

\section{FEDERAÇÃO CATARINENSE DE BOCHA E BOLÃO - FCBB. Regulamento Geral} Bolão - Bola $16 \mathrm{~cm}$. Disponível em:

<http://www.fcbb.com.br/site/downloads/2016_cbbb_bolao16_regulamentogeral.pdf> Acesso em: 11 mar. 2016.

FREUNDS KEGLER CLUB - FKC. O Nosso Esporte: Bolão Bola 16. Disponível em: < http://www.fkcbolao16.com.br/Bolao.asp> Acesso em: 10 mar. 2016.

HALL, Susan J. Biomecânica Básica. 4ํㅗㄹ ed. Rio de Janeiro: Guanabara, 2005.

HAMILL, Joseph; KNUTZEN, Kathleen M. Bases Biomecânicas do Movimento Humano. $2^{\mathrm{a}}$ ed. Barueri: Manole, 2008.

HOUGLUM, Peggy A; BERTOTI, Dolores B. Cinesiologia clínica de Brunnstrom. Barueri: Manole, 2014.

JARMEY, Chris; MYERS, Thomas W. O corpo em movimento: uma abordagem concisa. Barueri: Manole, 2008.

MÜLBAUER, VINÍCIUS A. Escola de Bolão: Como Jogar Bola 16. 2011.

PEREIRA, José M. Manual de Metodologia da Pesquisa Científica. 3aㅡ ed. São Paulo: Atlas, 2012.

PINTO, Andrea S. Análise Biomecânica do Membro Superior no Esporte Bolão e a Correlação dos Músculos Rotadores Internos e Externos do Ombro no Gestual Desportivo. 2002. f.63. Monografia (Graduação na Área da Saúde) - Curso de Fisioterapia. Universidade Tuiuti do Paraná, Curitiba.

SOUZA, Marcial Zanelli de. Reabilitação do Complexo do Ombro. Barueri: Manole, 2001.

TRIA, A. J. Lesões Ligamentares do Joelho. Rio de Janeiro: Revinter, 2002 WALKER, Brad. Lesões no Esporte: Uma Abordagem Anatômica. Barueri: Manole, 
2010.

WEINECK, Jürgen. Anatomia Aplicada ao Esporte. 18 ed. Barueri: Manole, 2013.

WORLD HEALTH ORGANIZATION. Obesity: Preventing and Managing the Global Epidemic. Report of a World Health Organization Consultation. Geneva: World Health Organization, 2000. p. 256. WHO Obesity Technical Report Series, n. 284 